\title{
Analysis on stability of dike in water diversion of river bank
}

\author{
Xiaocheng Su \\ School of Resources and Environment, University of Jinan, Jinan, China,250022 \\ suxiaocheng@tju.edu.cn
}

\begin{abstract}
The change of reservoir water level will affect the stability of the water, mainly in the soil pore water pressure changes and slope sliding surface parameters of the two aspects of weakening. The stability of the slope is analyzed, the results show that the stability of the slope due to the existence of pore water pressure during the whole change of the water level of the reservoir from the slope Significant changes have taken place. In order to solve this problem, the stability of slope is studied by using P LAX IS finite element program, and the state of embankment in different water level is simulated numerically. The results show that with the water level from low to high, slope stability first decreased after the increase in the change. Through this result can provide the basis for the safe operation of the reservoir.
\end{abstract}

Keywords: stability, dike, water level

\section{INTRODUCTION}

Dike works in the development of the national economy occupies an extremely important position, in which the river dike project since ancient times has made great contributions to mankind, embankment project with flood control, drainage, wind and storm surge and many other effects, because of its flood control Function is particularly significant, it has been the focus of attention of the country, but also because the dike project if the design is irrational easy to damage, so not only will not provide people with convenience and threaten the safety of human life. Therefore, the stability of the embankment analysis is particularly important ${ }^{[1]}$.

At present at home and abroad for the river bank revetment water level changes caused by changes in the stability of the dike analysis of the work involved in many aspects have also made great progress ${ }^{[2]}$. In addition, with the continuous development of software engineering, the use of software for slope or embankment stability analysis has become increasingly simple, and through the software to calculate the results and models can be more clearly show to people slope and embankment Changes in the degree of damage to the project and the rise and fall of the water level or other factors affect the safety factors such as changes in the safety factor of the slope or embankment works and so on. It provides a lot of convenience for people to carry out prevention work on slope and embankment works ${ }^{[3]}$.

In this paper, we discuss the problem of dam damage caused by water level change. Based on the principle of stability analysis, the finite element software is used to analyze the simple practical problems. Then, the model is established and solved. The end, the change in pore water pressure causes the stability of the slope to decrease first and then increase. 


\section{STABILITY ANALYSIS OF EMBANKMENT}

\section{The content of embankment stability analysis}

The analysis of embankment stability mainly includes: anti-sliding stability analysis and seepage stability analysis of two elements. The seepage stability analysis is mainly to calculate the ratio of astronomical descent and seepage, and the results of seepage calculation are used to analyze the infiltration stability of the embankment, and then the type of impervious deformation can be judged. The analysis of anti-slip stability analysis is mainly based on the stability of the embankment under certain conditions ${ }^{[4]}$.

\section{Dike stability analysis method}

The limit equilibrium method in the slope stability analysis method is the most widely used method in the slope stability analysis. The basic principle of the method is to divide the vertical slabs of the slope sliders, The equilibrium equation is analyzed and then the safety factor is solved. Assuming that the forces acting on the bars are different, the calculation model can be simplified to better reflect the actual situation. Due to the assumption that the different main methods are Bi Xiaopu method, the Swedish arc method and so on. Because of the limitations of the method, the complex stress can not reflect the true stress deformation field of the soil, so the finite element method is put forward, but this method belongs to the qualitative analysis method and therefore can not calculate the specific safety factor value ${ }^{[5]}$.

\section{Finite element method}

In this paper, Plaxis finite cloud software for numerical simulation, PLAXIS program is a powerful general geotechnical finite element calculation software. It has been widely used in the finite element analysis of various complex geotechnical projects. The influence of the sudden rise and fall of the reservoir water level on the dam stability, the soft soil foundation consolidation drainage analysis, the foundation pit precipitation seepage analysis and the complete fluid-solid coupling Analysis and so on ${ }^{[6]}$.

The finite element method can be used to analyze the slope stability problem, which can be divided into the following three steps, divided into pre-processing, calculation and post-processing. Among them, the pre-processing is to establish a finite element model at the same time division of the cell grid; post-processing is finishing the calculation results to facilitate the understanding of the results and extract information. The finite element method effectively overcomes the deficiency of the strip method, and takes into account the nonlinear constitutive relation of the soil. The adaptability of the complex boundary is also good, taking into account whether the slope is a dike, natural slope or excavation The slope also takes into account the effects of construction loading and the initial stress and strain behavior of the soil, so the finite element method is well established in terms of mechanism.

\section{ENGINEERING EXAMPLES}

The engineering example adopted in this paper is a river treatment river from the small river cliff gate - Ling Shan Tau section, the length of $7.675 \mathrm{~km}$, the total length of the cross-strait vice altar $6.455 \mathrm{~km}$, of which left bank embankment $3.414 \mathrm{~km}$, right bank embankment $3.041 \mathrm{~km}$, The top width of 4.5 meters, upstream batter and downstream slope ratio is 1: 2.5. Through the finite element software Plaxis established in Fig.1 basic geometric model.

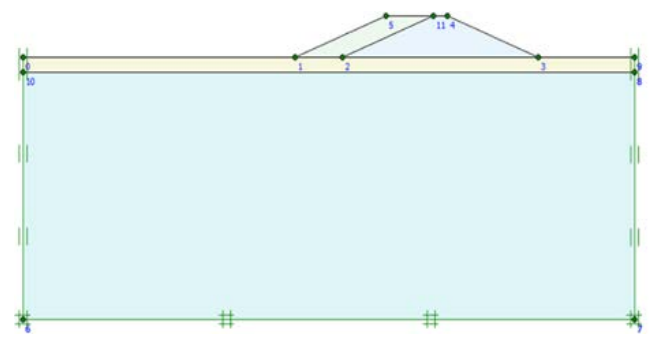

FIGURE 1. Embankment model 
The calculation process of the problem includes two steps: first, to calculate the initial stress to be set to plastic; second, reduce the high water level of the river, and thus make the sand layer within the pore pressure increases; third, calculate the safety factor, The method used to calculate the safety factor used in this practical problem is to reduce the phi / c calculation. Fig.2 is to set the general water level.

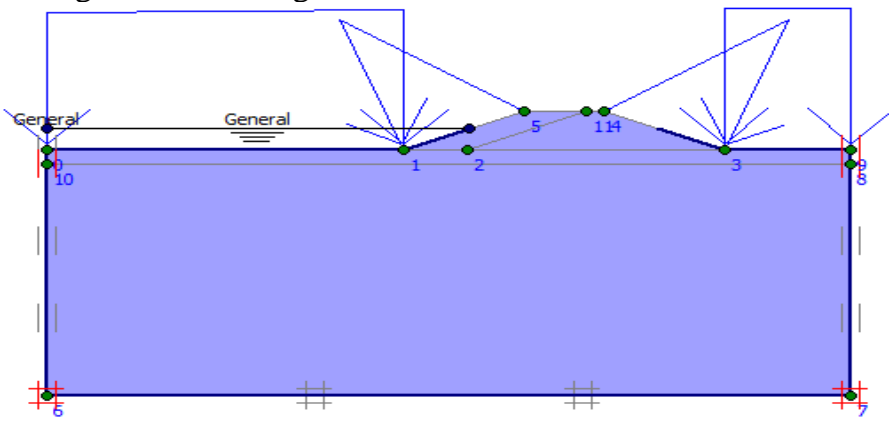

FIGURE 2. Set the general water level

After the completion of the above three steps can be showed. Fig.3 shows the effective stress distribution of the dam after the change of the water level. It can be seen from the figure that the change of the water level will obviously affect the stress distribution of the embankment. Before the water level is improved, the stress distribution is uniform and the stability of the embankment is better. And the two wings part of the force imbalance, which may lead to the entire embankment slip instability.

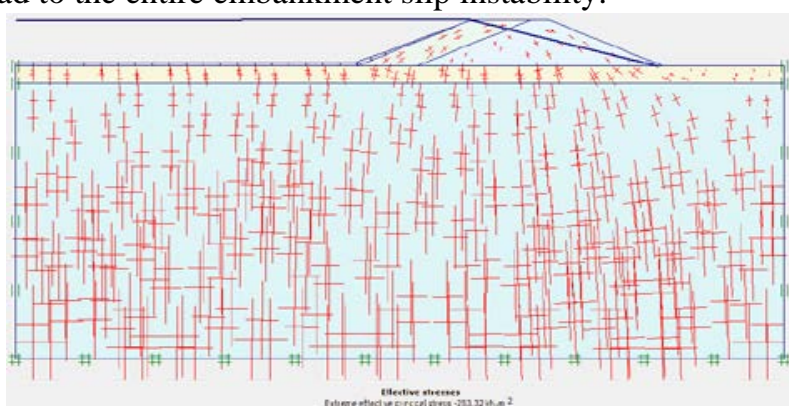

FIGURE 3. Effective stress of dam after rising water level

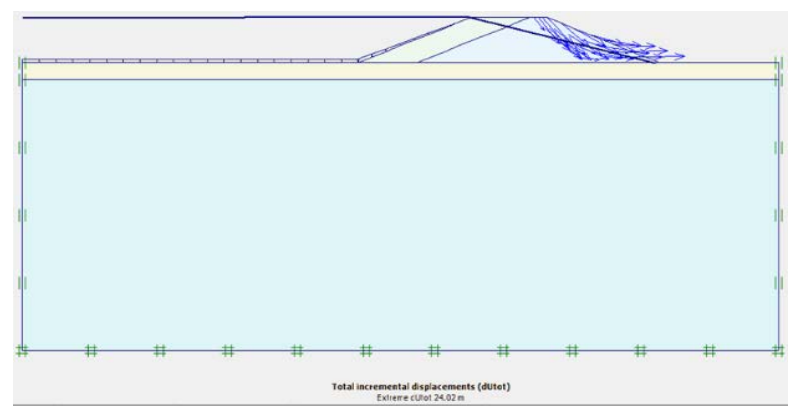

FIGURE 4. The total displacement of the dam

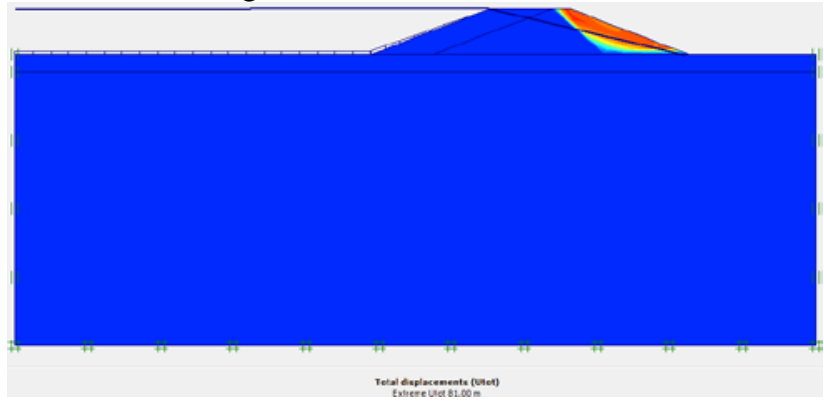

FIGURE 5. The total displacement increment of the dam

It can be seen from the above analysis of the program, water level changes significantly affect the strength of bank slopes, especially the total stress and effective stress distribution of the two sides of the slope will be a significant concentration, this will have a detrimental effect on the stability of the embankment. Therefore, it is important to control or adjust the running water level in the study of embankment.

The basic principle of the strength reduction method is to divide the slope strength parameter cohesion $\mathrm{C}$ and the internal friction angle $\Phi$ by a reduction factor $F$ to obtain a new set of $C$ 'and $\Phi^{\prime}$ and then enter it as a new set of material parameters, And then try to calculate, when the calculation does not converge, that is, after $\mathrm{n}$ times the input process, the resulting $\mathrm{C}$ and $\Phi$ value can not gradually converge to a precise solution, then the corresponding $\mathrm{F}$ is the minimum safety of the slope Coefficient, at which point the slope reaches the limit state, shear failure occurs, and the critical slip surface can be obtained. 
When the dike is a drainage, the water pressure will not be generated in the slope during the running water level change. The results of the stability analysis of the dike when the water level is changed by the procedure are shown in Table 1.

TABLE 1. The calculation results of the safety factor of pore water pressure are not taken into account

\begin{tabular}{cccc}
\hline The height of the water level drops $/ \mathbf{m}$ & 0 & 1 & 2 \\
\hline Safety factor & 1.849 & 1.158 & 0.976 \\
\hline
\end{tabular}

When the dike is undrained, the water pressure generated in the slope will grow rapidly during the running water level. The results of the analysis of the dike stability when the water level is reduced by the procedure are shown in Table 2.

TABLE 2. The calculation results of the safety factor of the pore water pressure

\begin{tabular}{cccc}
\hline The height of the water level drops $/ \mathbf{m}$ & 0 & 1 & 2 \\
\hline Safety factor & 1.847 & 1.021 & 0.806 \\
\hline
\end{tabular}

From the above results, it can be seen that the safety factor of the slope is obviously changed when the water level changes under the drainage condition, and the safety performance index of the water pressure slope in the slope is not drastically reduced. If the water pressure in the slope is taken into account in the calculation, the safety performance parameter obtained at that time is much lower than the calculation result when the water pressure in the slope is not taken into account. This shows that the increase of the water pressure in the slope during the water level decreases To the greater adverse effects.

\section{CONCLUSION}

According to the example, the factors that affect the slope stability include the shear index, the permeability coefficient, the velocity of the water level and the height of the water level decrease. The safety factor of the embankment gradually decreases when the water level begins to fall, but when the water level drops to a certain height, the safety factor increases gradually over time, which means that the slope has one of the most dangerous water levels. With the rise of the reservoir water level, the strength of the slope of the pore water pressure and sliding surface strength parameters weakened, will reduce the stability of the slope. When the water level reaches this most dangerous water level, the stability coefficient of the slope is the smallest, which requires analysis of the most dangerous water level in order to take effective measures to prevent the slope and embankment project damage.

\section{ACKNOWLEDGMENTS}

The study is financially supported by the science and technology planning project of colleges and universities in Shandong Province (J14LH01), University of Jinan Found and the National Natural Science Fund (XKY1135).

\section{REFERENCES}

1. Jibing Jiang, Study on the Influence of Water Level Drop on Reservoir Slope Stability [J], Foshan Shunde Water Resources and Hydropower Survey and Design Institute Co., Ltd., 2005, 4 (10): 12-14.

2. Huanxin Wu. Study on Comprehensive Evaluation System of Dangerous and Dangerous Reinforcement of Dangerous Reservoirs [D]. Shandong: Master's Thesis, Shandong University, 2009, 736-738.

3. GRIFFITHS D V,LANE P A. Slope stability analysis by finite elements[J]. Geotechique,1999,49(3):387-403.

4. Ganggang Wu, Shixiu He, Xumin Wang, Caixia Li .Study on stability of embankment when water level descends [J]. Geotechnical Foundation. 2005, 12 (19): 2-4.

5. HELMING R. Multiphase Flow and Transport Process in the Subsurface[M]. Berlin: Springer, 1997.

6. Xiaosong Tang, Yingren Zheng, Aiqing Wu, Chengqing Lin.Study on slope stability under seepage using PLAXIS finite element program [J] .Chinese Journal of Science, 2006,8 (23): 13-16.

7. Kaiwu Chen, Shibing Hu, Guangpu Song.Study on reinforcement of dangerous reservoirs [J] .Chinese Journal of Water Resources,2005,4(3):30-32

8. Yan-kun LI, Yan-jun Guo, Fengyao Zhao.Three-dimensional finite element analysis of Mawang reservoir masonry arch dam [J]. Hydropower Engineering,2011,29(7):62-63 